\title{
Testimonio e intimidad en las memorias de segunda generación: ¿Quién te creés que sos? (2012), de Ángela Urondo Raboy*
}

Laura Fandiño ${ }^{1}$

Universidad Nacional de Córdoba (Argentina)

\section{Resumen}

La literatura de posdictadura en Argentina operó un giro en el nuevo milenio a partir de la intervención de los hijos de quienes fueron protagonistas de los acontecimientos históricos traumáticos de la última dictadura cívico-militar (1976-1983). En este trabajo proponemos una lectura del texto de carácter testimonial ¿Quién te creés que sos?, de Ángela Urondo Raboy, para examinar los elementos documentales y que pueden asociarse a los géneros de la intimidad. Nuestra lectura apunta a señalar la transformación del testimonio en las memorias de segunda generación, en la medida que incorpora la intimidad como parte necesaria para dar cuenta de la complejidad de las vidas afectadas por la violencia política.

Palabras clave: memoria, narrativa de los hijos, testimonio, intimidad.

\section{Abstract}

The post-dictatorship literature in Argentina operated a turn in the new millennium from the intervention of the children of those who were subjects of the traumatic historical events that took place during the last civic-military dictatorship (1976-1983). In this work we propose a reading of ¿Quién te creés que sos?, by Angela Urondo Raboy, to examine in this text of testimonial nature the documentary elements as well as those that can be associated with the genres of privacy. Our reading aims to point out the emphasis of the testimony in the second generation memories to the extent that it incorporates within itself privacy as a necessary constituent to account for the complexity of the lives affected by political violence.

Keywords: memory, children's narrative, testimony-privacy

\footnotetext{
* Testimony and privacy in second generation memories: ¿Quién te creés que sos? (2012), by Ángela Urondo Raboy

Recibido: 24 de octubre - Aprobado: 21 de noviembre

${ }^{1}$ Doctora en Letras por la Universidad Nacional de Córdoba (Argentina). Docente e investigadora de la Facultad de Lenguas de la Universidad Nacional de Córdoba. e-mail: laurafnd09@gmail.com
} 


\section{Introducción}

Los acontecimientos políticos de la última dictadura cívico-militar en Argentina, que dejaron improntas traumáticas en el tejido social, dieron lugar a una cuantiosa producción simbólica extendida hasta la actualidad y que se asocia a formas de la violencia contemporánea, como ocurrió recientemente con la desaparición forzada de Santiago Maldonado, luego aparecido, sin vida. ${ }^{2}$ La emergencia de las voces de los hijos de sobrevivientes o desaparecidos durante el terrorismo de Estado trajo aparejada la incorporación de nuevos temas y tonos (Fandiño, 2016) en torno a la interpretación de ese pasado desde los encuadres sociohistóricos actuales de la memoria. Entre la producción de los hijos se destaca teatro, cine, fotografía, poesía, novelas y textos situados en espacios intersticiales desde el punto de vista genérico, pendulando entre lo autobiográfico y lo ficcional ${ }^{3}$.

Este trabajo propone una sucinta reflexión sobre la relación entre la noción de "género" y la de "intimidad", asociada esta última a un retorno de la idea de "sujeto" que, alejada del decreto barthesiano de la muerte del autor, parece cobrar una fuerza inusitada en la literatura contemporánea. Mencionamos las principales vertientes que abordaron el estudio del "testimonio" y de la figura del "testigo", y recuperamos algunos aspectos clave para proponer una lectura de las memorias de segunda generación, en particular a partir de ¿Quién te creés que sos?, de Ángela Urondo Raboy. Nos detenemos inicialmente en la parte testimonial del texto y consideramos luego la presencia de otras ligadas a géneros de la intimidad como fragmentos de diario personal, notas y poemas. Nuestra hipótesis de lectura es que, si bien el texto se organiza en apartados, dando cuenta de una conciencia que distingue los hechos y los documentos que testifican su existencia de otros relatos que giran en torno a esos hechos vinculados a la historia de vida de la protagonista -notas, poemas, impresiones, sueños-, todos en conjunto constituyen un documento testimonial, pues las marcas en el cuerpo y la subjetividad de la testigo-hija se erigen en material que también testifica el impacto de la violencia política sobre las vidas privadas e íntimas.

\footnotetext{
${ }^{2}$ Santiago Maldonado fue un tatuador de 28 años que desapareció el 1 de agosto de 2017, en ocasión de la represión de Gendarmería Nacional por la protesta de la comunidad mapuche Pu Lof, en Resistencia Cushamen (provincia argentina de Chubut). El 17 de octubre fue encontrado su cuerpo en cercanías de donde se había denunciado su desaparición. El artista visual cordobés Gabriel Orge proyectó la imagen de Santiago Maldonado sobre el muro de un edificio integrándola así a su serie Apareciendo (http://www.lavoz.com.ar/politica/el-rostro-de-santiagomaldonado-aparecio-en-un-edificio-de-cofico)

${ }^{3}$ Por ejemplo, citamos las novelas de Laura Alcoba, La casa de los conejos y El azul de las abejas; Aparecida, de Marta Dillon; Diario de una princesa montonera -110\% Verdad-, de Mariana Eva Pérez; Soy un bravo piloto de la Nueva China, de Ernesto Semán; y Los topos, de Félix Bruzzone, entre otros.
} 


\section{Géneros e intimidad}

Los géneros discursivos, como señala el filósofo ruso Mijaíl Bajtín ([1979] 2003), tienen vida, puesto que son permeables a cambios y transformaciones en función de diversos aspectos que operan como condicionantes: por ejemplo, los sujetos que, desde cierta posición social o visión de mundo, los recuperan en determinadas coordenadas históricas. En cada actualización de un género dado se juega un doble movimiento entre la conservación y la renovación. En otras palabras, es posible reconocer el pasado de un género determinado en un enunciado dado y advertir al mismo tiempo la novedad que introduce. En consecuencia, referirnos al carácter vital de los géneros implica atender a la dinámica entre la conservación de elementos, que permiten reconocerlo como $x$ género, $y$ sus transformaciones. En el ámbito del arte, en general, y del literario, en particular, asistimos, desde el decreto de la caída de los grands récits en la segunda mitad del siglo XX, a una enorme permeabilidad entre los géneros que dificulta $y$, en ocasiones, hace fracasar las intenciones clasificatorias de críticos, estudiosos de la literatura y del discurso en general. Las fronteras porosas, las mezclas o hibridaciones de códigos genéricos diversos no son, en este sentido, una novedad.

Junto al retorno de un sujeto que ya se sabe no monológico ni monolítico, sino múltiple, fragmentario, descentrado y cambiante, tuvo lugar un profuso regreso de escrituras del "yo" que recuerda sus antepasados genéricos, pero que rápidamente ha ido confundiendo sus fronteras. ${ }^{4}$ De allí el esfuerzo por distinguir memorias, autobiografías, novelas autobiográficas, autoficciones, autofiguraciones, novelas testimoniales y non fiction novel, lo que ha

\footnotetext{
${ }^{4}$ Beatriz Sarlo (2005) recupera la noción de "giro subjetivo", contemporánea a la de "giro lingüístico" en los sesenta y setenta, para explicar la actual revaloración que la academia y el mercado realizan de la rememoración de la experiencia, la reivindicación de la primera persona y de la dimensión subjetiva. Sostiene Sarlo (2005): “[...] la actual tendencia académica y el mercado de bienes simbólicos que se propone reconstruir la textura de la vida y la verdad albergadas en la rememoración de la experiencia, la revaloración de la primera persona como punto de vista, la reivindicación de una dimensión subjetiva, que hoy se expande sobre los estudios del pasado y los estudios culturales del presente, no resultan sorprendentes. Son pasos de un programa que se hace explícito, porque hay condiciones ideológicas que lo sostienen. Contemporáneo a lo que se llamó en los setenta y ochenta el 'giro lingüístico' de la historia, o acompañándolo muchas veces como su sombra, se ha impuesto el giro subjetivo" (21-22). "Se trata, de algún modo, de una democratización de los actores de la historia, que da la palabra a los excluidos, a los sin título, a los sin voz. En el contexto de los años posteriores a 1968, se trató también de un acto político: Mayo del 68 fue una gigantesca toma de la palabra; lo que vino después debía inscribir este fenómeno en las ciencias humanas, ciertamente, pero también en los medios -radio o televisión- que comienzan a solicitar más y más al hombre de la calle" (Wieviorka citada por Sarlo, 161).
} 
dado como resultado un prolífico corpus teórico y crítico desde la década del 70 hasta la actualidad. Así, los espacios (auto)biográficos y el giro hacia manifestaciones de la intimidad son memoria viva de sus antepasados genéricos, pero, al mismo tiempo, dan cuenta, en el contexto del mundo globalizado, del engendramiento de nuevas subjetividades.

Leonor Arfuch $(2013,2016)$, aguda estudiosa de los espacios autobiográficos y de las cronotopías de la intimidad, expresa que las fronteras entre lo público y lo privado, tal como estaban delimitadas en la vida moderna, se han desplazado en la actualidad, y que en realidad, público y privado -y lo íntimo como expresión de lo privado- ya no forman parte de una díada opositiva. El lugar que cabe en la actualidad a la intimidad es insoslayable. Arfuch (2016) refiere que:

Así como lo público y lo privado no pueden pensarse ya como dominios autonómicos con incumbencias -y sentimientos- específicos, sino más bien como espacios simbólicos mutuamente implicados, en constante interacción -e intersección-, la intimidad componente esencial de lo "privado"- parece alcanzar hoy un punto extremo [...]. No sólo es posible expresarla públicamente en sus acentos más recónditos [...], sino que irrumpirá a su vez en el "altar doméstico" a través de las pantallas [...] como tematización casi maníaca [...]" (2016: 237- 238)

Ante las críticas y sospechas fundadas en torno de diversas formas de exhibición de la más profunda intimidad en los espacios públicos, especialmente la televisión, Arfuch propone pensar también la potencia de esa intimidad y su investidura afectiva en el espacio político como motor de transformación de la sociedad en una relación positiva con la democracia. ¿Qué lugar ocupan, entonces, los géneros de la intimidad en la literatura testimonial de los hijos?

\section{Testimonio}

Los testimonios de los sobrevivientes de acontecimientos traumáticos, que plantearon para la historiografía la crisis del testimonio (Ricoeur, 2008), tuvieron como efecto la producción de una cuantiosa bibliografía. Desde el ámbito de los Estudios de la Memoria, instaurado en torno del Holocausto o Shoa -entre cuyos testigos faro podemos mencionar a Primo Levi y Jorge Semprún-, se 
publicaron textos clave que son en la actualidad lectura insoslayable sobre el género, sus usos y la figura del testigo (Agamben, 2000; Ricœur, 2008; Robin, 2012,). En Latinoamérica y en EE.UU el intenso debate que tuvo lugar hacia fines de la década del noventa en torno al testimonio de Rigoberta Menchú (Casa de las Américas, 1983), Me llamo Rigoberta Menchú y así me nació la conciencia, firmado por Elizabeth Burgos-Debray, inauguró un importante corpus de estudio crítico que entronca con el patrón testimonial de las formaciones revolucionarias de los años sesenta y setenta ${ }^{5}$. Así mismo, en el Cono Sur y en Argentina, particularmente, los intelectuales reflexionaron sobre los testimonios de los sobrevivientes de las dictaduras (Jelin, 2001; Sarlo; 2005).

Algunos ejes de estudio en torno al género consideran la figura del testigo, su carácter de sujeto subalterno y la articulación entre la historia colectiva y la historia personal; la relación del testimonio con la historiografía, con la verdad, con la institución literaria, con la política, el problema de la autoridad del testimoniante, el de la construcción narrativa del testimonio y su dimensión ético-estética. En un esfuerzo por delimitar lo que sería propio de este género, y en el contexto de su institucionalización por la Casa de las Américas, Margaret Randall (2002) distingue el testimonio en sí del testimonio para sí. En la primera denominación incluye la literatura testimonial (novelas, obras de teatro que dan testimonio de un hecho o época, el periodismo, los documentos cinematográficos o colecciones de fotografías). Es decir, Randall considera, en este sentido, diferentes textos culturales en tanto obras con valor testimonial. En cuanto género que se diferencia de otros, el testimonio para sí, la autora reconoce los siguientes elementos: la utilización de fuentes directas, la entrega de una historia contada a partir de las voces de los protagonistas de un hecho, la inmediatez (el relato de un hecho vivido, una experiencia particular), el uso de material secundario (introducciones, entrevistas de apoyo, documentos y materiales adicionales) y una alta calidad estética referida al montaje.

Ahora bien, los textos testimoniales no son meras transcripciones de acontecimientos más o menos significativos, sino que plantean una serie de encrucijadas teóricas en razón de las tensiones que establecen entre realidad y ficción, entre los hechos y su montaje narrativo. El estatuto del "yo" testimonial se encuentra en los límites de los términos texto-realidad. Beverley (2002) recupera una cita de Elzbieta Sklodoswska que creemos significativa en este sentido:

\footnotetext{
${ }^{5}$ Consignamos en el apartado bibliográfico la compilación realizada por John Beverley \& Hugo Achúgar (2002).
} 


\begin{abstract}
Sería ingenuo asumir una relación de homología directa entre la historia y el texto. El discurso del testigo no puede ser un reflejo de su experiencia, sino más bien una refracción debida a las vicisitudes de su memoria, su intención, su ideología. La intención y la ideología del autor-editor se sobrepone al texto original, creando más ambigüedades, silencios, lagunas en el proceso de selección, y montaje y arreglo del material recopilado conforme las normas de la forma literaria. Así pues, aunque la forma testimonial emplea varios recursos para ganar en veracidad y autenticidad -entre ellos el punto de vista de la primera persona-testigo- el juego entre ficción e historia aparece inexorablemente como un problema (en Carr, 2002: 90-91).
\end{abstract}

En relación con lo antedicho, Ana María Amar Sánchez (1990), en "La ficción del testimonio", propone para el género de no-ficción dos elementos que definen y señalan su ambigua posición intersticial, y que creemos apropiado recuperar: por una parte, destaca la interdependencia formal entre los textos de no-ficción y el resto de la producción de la obra de un mismo autor. Por otra, y es esta la que nos interesa específicamente, postula la narrativización o ficcionalización de "figuras provenientes de lo real que pasan a constituirse en personajes y narradores". Sigue la autora:

Se los lleva a primer plano, se los "enfoca de cerca", individualizando y volviendo sujetos a aquellos que en un informe periodístico quedarían en el anonimato. Las categorías narrativas de personaje y narrador están aquí profundamente contaminadas de elementos referenciales que se "literaturizan" en el texto, son ejes que permiten el pasaje de lo real a lo literario y participan de ambos al mismo tiempo (449).

Es así como los sujetos en el texto participan de un doble espacio y son agentes de la transformación narrativa estableciendo un puente entre lo real y lo textual. Consecuentemente, todo relato pasa por la posición del sujeto testimoniante. Se trata entonces de revisar el testimonio que, como uno delos géneros del “yo", propicia el debate por la consideración de sus límites, especificidades y entrecruzamientos con otros géneros (crónicas, memorias, etc.), de la tensión que plantea entre lo público-histórico, lo privado y la intimidad, así como entre lo referencial y su construcción narrativa. Creemos que en esta constelación de problemáticas debemos repensar hoy el testimonio, sus transformaciones, y particularmente, aquello que de testimonial se fragua en las narrativas de la segunda generación donde el pasado continúa presente y la interioridad asume un lugar clave. 


\title{
Narrativas de segunda generación: lo testimonial en la memoria de una hija
}

En La palabra justa, Miguel Dalmaroni (2004) señala que las narrativas de los derechos humanos y de los hijos, específicamente, se caracterizan por la mezcla de códigos genéricos, lo que produce

\begin{abstract}
[...] combinaciones novedosas y, a la vez, son relatos donde puede darse, por lo menos en alguna medida, un desprendimiento estructural [...] respecto de los procedimientos y de las retóricas de control ideológico o moral que suelen ser tan fuertes en el patrón testimonial y, en general, en el discurso político vinculado con las formaciones revolucionarias de los años setenta; esa plasticidad que abre el género a una construcción no prevista de sentidos puede deberse a varios factores, pero uno que resulta decisivo está en la intervención inevitable de las biografías privadas, de la esfera de la más recóndita intimidad, en un relato de extrema significación colectiva (119).
\end{abstract}

En la Argentina del nuevo milenio toman fuerza y visibilidad las narrativas de los hijos, que comienzan a desarrollarse con cierta organicidad a mediados de la década del noventa desde la agrupación H. I. J. O. $S^{6}$, pero también, y significativamente, en el ámbito del arte (cinematográfico, fotográfico, teatral, literario). En las expresiones artísticas de los hijos se amalgaman, intersectan o entrecruzan lo público-político y lo privado-familiar e íntimo, constituyendo un espacio cuya especificidad se trama en la conformación de una zona intersticial que transgrede las fronteras de distintos géneros. Este carácter de plasticidad genérica puede advertirse en el texto de Ángela Urondo Raboy, ¿Quién te creés que sos?, donde convergen documentos, citas de diferentes textos, crónicas, fotografías, poemas, fragmentos de anotaciones, recortes periodísticos y testimonios de sobrevivientes, que operan como mediaciones para la reconstrucción del linaje de la narradora interrumpido por la violencia política de la última dictadura cívico-militar argentina. Sin embargo, no se trata de un mosaico de textos organizados al azar, sino que, en su fragmentariedad, configura una narrativa memoriosa donde emerge

\footnotetext{
${ }^{6}$ H.I.J.O.S (Hijos e Hijas por la Identidad y la Justicia contra el Olvido y el Silencio) es la organización argentina de derechos humanos originada en 1995 y nucleada en torno a "la exigencia de justicia, la necesidad de reconstruir la historia personal, reivindicar las luchas de nuestros padres, madres y los 30. 000 compañeros detenidos-desaparecidos; la exigencia de la restitución de la identidad de nuestros hermanos apropiados". (http://www.hijos-capital.org.ar/)
} 
una figura testimoniante intensamente dialógica -que no elude las lagunas de la historia-, reparadora, y en este sentido, moral.

Ángela es hija de Alicia Cora Raboy y Francisco "Paco" Urondo. Tras el asesinato de su padre y el secuestro y la desaparición de su madre, Ángela, de casi un año, es recuperada por su abuela materna y su tía paterna en la Casa Cuna de Mendoza, donde había sido trasladada por los militares. De allí sobreviene una sucesión de acontecimientos en su vida que, durante muchos años, a causa de los silencios en el núcleo familiar que la adopta, obturará el saber acerca de su origen. Recién en su avanzada adolescencia, conocerá su verdadera filiación y decidirá comenzar a reconstruir y resignificar la historia de su vida en un proceso de recuperación y reinscripción de su identidad.

¿Quién te creés que sos? proyecta la historia de vida de la narradoraprotagonista-testigo atravesada, directa y catastróficamente, por la violencia política en el país. En este sentido, el texto contiene un valor testimonial insoslayable. Como niña sobreviviente, la reconstrucción de la historia de sus padres y la propia es lacunar, faltan recuerdos, faltan datos. Por ello su memoria se conforma mediante una narrativa que requiere la incorporación de la palabra del "otro" para rearmar el mapa de los acontecimientos, conferirle sentidos, y de este modo, resignificar la historia de vida y definir la identidad. En esta dirección, es posible considerar con Beverley (2002) que "la autoridad del testimonio deriva del hecho de que el narrador es alguien que ha presenciado o experimentado en propia persona -o indirectamente a través de la experiencia de amigos, familiares y vecinos- los acontecimientos que narra" (60), y por lo tanto, se erige en fuente de conocimiento ${ }^{7}$. La dificultad que yace en este testimonio, y que se patentiza en la fuerza dialógica de la primera parte, es que la protagonista presencia y experimenta algunos de los hechos de

\footnotetext{
${ }^{7}$ Uno de los interrogantes que generó el debate en torno al testimonio de Rigoberta Menchú respecto a la problemática de la autoridad del testimonio, se refiere a quién puede reconstruir mejor el pasado: los que lo han vivido o los profesionales que, mediante técnicas científicas pretendidamente objetivas, se sienten autorizados para narrarlo. De cierta forma, este debate se recupera en el nuevo milenio cuando Beatriz Sarlo reflexiona sobre los alcances de la noción de "Posmemoria", formulada a fines de la década del noventa por Marianne Hirsch en el ámbito de los Estudios Culturales, y específicamente, de los Estudios de la Memoria. Uno de los puntos de este debate es la relación diferencial que el profesional (por ejemplo, el historiador) mantiene con los documentos y el involucramiento personal, afectivo y moral, que sostienen con el pasado los sobrevivientes y las generaciones que le siguen, particularmente los hijos. El punto de discusión se articula, en este sentido, con la idea de "mediación". Sarlo sostiene que toda memoria es mediada y fragmentaria, y advierte que lo específico de la Posmemoria sería el vínculo afectivo con el pasado. Ahora bien, en el ámbito del arte, los hijos construyen narrativas con valor testimonial y a partir de ellas se proyectan poéticas y políticas de la memoria con particularidades generacionales que las tornan ricos espacios de configuración de sentidos.
} 
primera mano; pero era entonces una niña de poco menos de un año. Sin embargo, los sueños y pesadillas recurrentes que tiene durante su infancia y adolescencia se erigen también en fuentes con valor testimonial.

\section{Variaciones genéricas sobre un tema}

¿Quién te creés que sos? se divide en tres partes que son clave para considerar la transformación del testimonio en relación con la historia de vida de la protagonista. Estas son: "Documentos (palabras inapelables)", "Crónicas (palabras hacia afuera)" y "Conclusiones (palabras interiores)". Estos títulos organizan una cronotopía de la memoria asentada en $a$ ) documentos que ofician como pruebas inapelables, como res factae (los hechos acaecidos); b) crónicas de la hija-testigo que recuperan su recorrido de demanda de justicia por sus padres y por su propia reinscripción en la genealogía familiar, donde entra en contacto con los otros -sobrevivientes, militantes y agrupaciones- (hacia afuera); y, por último, $c$ ) las conclusiones están constituidas por textos que dialogan más intensamente con géneros de la intimidad (fragmentos de diarios, impresiones, poemas y anotaciones) $)^{8}$. Si bien el trabajo de montaje puede perseguirse a lo largo de todo el texto, son las crónicas y las conclusiones las que conforman, en sentido estricto, la res fictae, es decir, la construcción narrativa a partir de los documentos y la experiencia de la narradora. En este sentido, entendidos como vectores cronotópicos de la memoria, creemos que la prueba de la factualidad de los acontecimientos que otorgan los documentos, lo "hacia afuera" y lo "hacia adentro" o "factualidad de lo íntimo", constituyen una poética testimonial inédita.

Esta organización de las partes del texto proyecta una conciencia creadora que delimita el orden de lo público, lo privado familiar compartido en lo público, y lo íntimo. Sin embargo, cada una de las partes gira en torno a los mismos aspectos de la historia de vida de la protagonista que se liga con la historia del país. En el sentido estricto de la definición del "género" (Randall, 2002), sería testimonial la primera parte que incorpora documentos en una tarea de montaje de archivos diversos: actas, testamentos, cartas, fotografías, informes, testimonios de terceros que apoyan la construcción del propio relato. Esta concurrencia de distintos tipos textuales a modo

\footnotetext{
${ }^{8}$ Recuperamos la noción de "cronotopo" de Mijaíl Bajtín (1991) que refiere "a la conexión esencial de relaciones temporales y espaciales asimiladas artísticamente en la literatura [...] expresa el carácter indisoluble entre espacio y tiempo (el tiempo como la cuarta dimensión del espacio" (237).
} 
de archivos apunta a probar, como señalamos, los acontecimientos del pasado. Las otras dos partes, la crónica y distintos géneros de la intimidad, entran en contacto con lo testimonial en tanto dan cuenta también de la vida de la protagonista. Se configura de este modo un espacio autobiográfico, de la intimidad, pero conservando su valor testimonial, puesto que en estos apartados se encuentran las marcas de la historia en lo subjetivo y tienen, por tanto, significación colectiva. Varían entonces los códigos genéricos convocados, pero no el tema central sobre el que se testimonia -el proceso de verdad, de recuperación de la identidad, la recolocación en el linaje-. Así lo testimonial aloja en este texto diversos géneros que acentúan ya lo público, ya lo privado o íntimo, porque el testimonio de la propia vida no está escindido de la historia colectiva.

\section{La parte de los documentos}

La primera parte, titulada "Documentos (palabras inapelables)" puede leerse a partir de tres secuencias: 1) la familiar, constituida por un testamento, una carta y fotografías; 2) la política, incorpora la crónica, testimonios, un acta de procedimiento policial y un recorte de periódico. Estos textos giran en torno a las vicisitudes que lleva a la familia Urondo Raboy a Mendoza, en el marco de su militancia en Montoneros; el episodio de la persecución y muerte de Paco Urondo; la detención ilegal de Alicia Raboy y el destino de Ángela; y 3) la referencia a leyes y acontecimientos judiciales que remiten a la memoria histórica y a la construcción de una identidad nacional diferente a partir de la recuperación de historias silenciadas. En las dos últimas secuencias la intensidad dialógica, como observaremos, se exacerba.

La primera secuencia documental atestigua la vida privada y familiar de padre, madre e hija en el contexto de la clandestinidad. Esta parte opera, a partir de los textos que la componen, como factualidad atestiguada. Es decir, da cuenta de episodios que remiten a la vida antes de la catástrofe: al hecho de que hubo una vida antes. Entre los documentos se encuentra el reconocimiento de Francisco Urondo de su paternidad a través de un testamento que, si bien no tiene validez legal, tiene valor para la hija, porque revela, por parte del escritor, su "clara intención de ser padre" (2012: 12). La presencia de la copia del documento original, de puño y letra de Urondo, que ha quedado por décadas en el círculo de la familia, funciona como prueba testimonial. También la carta que Alicia Raboy, ya en la clandestinidad, con Urondo y Ángela, envía a la madre, donde refiere aspectos de la vida cotidiana, funciona como prueba de la existencia 
de ese antes. En la misma línea de los documentos que recuperan la vida familiar con anterioridad a la tragedia de la muerte violenta y la desaparición, se encuentra la foto de Urondo -fragmentada debido a la clandestinidad- con Ángela en el regazo y la foto de la niña con su madre.

La siguiente secuencia se organiza en dos partes: los textos que trazan una narrativa polémica en torno a las causas del traslado de la familia a Mendoza, en el seno de la organización Montoneros, y los documentos oficiales y noticias de los militares que manipulan y malversan los datos. Los fragmentos testimoniales sobre el destino de la familia introducen las voces de Rodolfo Walsh, Gabriela Esquivada, la visión de Lili Massferro, la palabra de Horacio Verbitsky. En esta parte, el texto se torna especialmente controvertido en relación con la conducción Montoneros, donde el traslado de la familia a Mendoza es interpretada como un castigo a partir de la relación extramatrimonial de Urondo con Raboy ${ }^{9}$. Desde la cita del artículo 16 del Código Montonero, "que penaba con degradación y arresto la infidelidad conyugal" (23), hasta las negaciones de Firmenich ${ }^{10}$ de la derrota que condujo a muchos militantes a una muerte segura, el texto pone en cuestión la narrativa heroica que sostienen algunos sobrevivientes de la organización. La condición "inapelable" de estos documentos se trama en el pacto fiduciario, en la creencia que la narradora establece en el diálogo con los otros, un diálogo necesario por cuanto hay episodios de ese pasado traumático que vivió, pero que no puede recordar, y necesario también para recuperar otros hechos que no experimentó de primera mano, pero que resultan fundamentales para reconstruir e interpretar su historia de vida. De esta manera, la narradora, testimoniante de segundo grado, acredita y autoriza este conjunto de textos testimoniales en relaciones de asentimiento o distanciamiento, e introduce, en ocasiones, precisiones para elaborar sus propias lecturas y puntos de vista.

Por otra parte, se cita en el texto el Acta del procedimiento policial de la persecución y el destino de los padres de Ángela, plagada de falsedades, como se probará en el Juicio por Delitos de Lesa Humanidad de Mendoza (2010-2011), y un recorte del diario Los Andes, de la misma ciudad, que transcribe, sin corroborar los datos, la información malversada, el "rosario de mentiras" (37) que "baja" del ámbito militar a los medios. Textos estos inapelables en su condición de falsedad, malversación, inmoralidad.

\footnotetext{
9 "El castigo" se intitula uno de los apartados de esta parte (23).

${ }^{10}$ Mario Eduardo Firmenich fue uno de los fundadores de la organización guerrillera Montoneros y uno de sus jefes principales entre 1970 y 1983.
} 
En la última secuencia, se revela la importancia de la verdad y la memoria histórica por medio de la intervención de la justicia. A través de la cita de diversos textos judiciales se da cuenta del proceso de reparación de la memoria en el país, se incorpora el de nulidad de las leyes de Obediencia Debida y Punto Final, la Resolución de la Corte Suprema que decreta su invalidez e inconstitucionalidad, y a modo de informe, los datos que llevan al proceso de enjuiciamiento o Jury a los magistrados cómplices del terrorismo de Estado. Luego, se incorporan fragmentos de testimonios del Juicio Oral por Delitos de Lesa Humanidad celebrado en Mendoza entre 2010 y 2011, en el que se trata el caso Urondo-Raboy y donde Ángela interviene como testimoniante. Finalmente, se reproduce el documento de la sentencia. En el apartado titulado "Será justicia" (54) se recuperan fragmentos de las conclusiones del juicio por Alfredo Guevara (hijo), abogado de la querella, donde se hace hincapié en "La decisión política de nuestro país al abrir una etapa de reparación con verdad, memoria y justicia a partir de la presidencia de Néstor Kirchner [que] constituye entonces la posibilidad de construcción de una identidad nacional distinta del legado de la dictadura militar" (54). Junto a todos los esfuerzos de reparación de la verdad, los testimonios del juicio recobraron las historias borradas y silenciadas por el "espanto institucionalizado", y en su conjunto, el proceso y las sentencias posibilitaron una relectura de la historia.

En la narrativa memoriosa que compone la hija, la selección y el montaje de los documentos, como advertimos a través de las secuencias, atestiguan la vida privada que no puede desvincularse de los acontecimientos de orden público que condujeron a la destrucción de la familia. En el proceso de una narrativa de recomposición del propio lugar en la genealogía a causa de la violencia política, se muestra cuánto de público, de cosa política, opera en lo privado y, como observamos en adelante, en lo íntimo.

\section{Cuando lo personal es político: intimidades que importan}

Hugo Achúgar (2002) señala que el testimonio es un discurso acerca de la vida pública o acerca del "yo en la esfera pública", a diferencia de la autobiografía, que es un discurso acerca de la "vida íntima" o interior (68). En este sentido, Carr (2002) destaca que, mientras lo autobiográfico hace foco en la singularidad de cada vida, el testimonio da cuenta de un sujeto plural implícito o explícito. En las narrativas de los hijos, en general, y en el texto que consideramos particularmente, lo público y lo íntimo aparecen involucrados como parte del testimonio. La división del texto y sus títulos orientan 
una conciencia entre la actuación pública de la hija testimoniante (testigo del juicio, participante de actos de memoria, los vínculos con los organismos de derechos humanos, con los sobrevivientes, etc.), donde se inscribe la singularidad en lo colectivo, y aquello que es del orden de lo personal y lo íntimo, es decir, la historia de vida condicionada por los acontecimientos de la violencia política.

La parte de las "Crónicas (palabras hacia afuera)" abarca un conjunto de narraciones que involucran los aspectos públicos de la lucha y la búsqueda de Ángela, como el recorrido por los lugares de Mendoza donde tuvieron lugar los hechos, el juicio, su propio testimonio y otros vinculados a la vida privada, pero como efecto de lo político: su adopción, los recuerdos de la infancia, el silencio familiar en torno al destino de sus padres, la vida en el seno de la familia adoptante, sueños, enfermedades, el proceso de desadopción, el reencuentro con la familia Urondo. En esta parte se incorpora también el paso de Ángela por la agrupación H. I. J. O. S., la recuperación de la historia de sus padres, especialmente de la madre, y tiene lugar también una visión crítica de Montoneros.

Es posible advertir un movimiento de este apartado que parte de las acciones públicas, se interna luego en lo privado e íntimo -como los sueños y la vida en el seno de la familia adoptante-, para retornar luego a lo público (H. I. J. O. S., Montoneros, voces de conocidos de los padres), como un recorrido necesario que permite a la narradora reinscribirse en el linaje familiar y comprender la recuperación de su identidad como "una construcción colectiva" (182).

En las "Conclusiones (palabras interiores)" se rescatan recuerdos de la infancia, diversos pensamientos sobre la propia vida, la orfandad, los discursos oficiales en torno a los desaparecidos, el distanciamiento de ciertos eslogánes y construcciones del periodo, entre otros asuntos. En esta parte se hallan inscriptas las anteriores, pero abordadas desde las reflexiones y vivencias personales de esta hija, que evidencian las complejidades del proceso interno que acompaña la reinscripción de su identidad en términos afectivos. Destacan en estas "Conclusiones" un conjunto de textos que incorporan una reflexión sobre el vínculo entre lenguaje y violencia. A modo de ejemplo, referimos el título de algunos: "Des existir", "Matria", "Caer no es caer", "Incondolentes", "Pre-juicio", "Duelar", "Lástima dura", "Des Espera", "Dos de moños". A través de estos juegos del lenguaje, que implican transformaciones, neologismos y descomposición de palabras referidas al campo semántico de la desaparición forzada de personas, se advierte un gesto reflexivo que apunta a deconstruir las malversaciones del lenguaje, los lugares 
comunes y las cristalizaciones de los sentidos como efecto de la violencia política para evidenciar la carne herida que se oculta detrás de las palabras. En "Caer no es caer", leemos:

\begin{abstract}
Chupar no es chupar/ Cita no es cita/ Dar no es dar/ Caer no es caer/Soplar no es soplar/ Pinza no es pinza/ Fierro no es fierro/ Máquina no es máquina/ Capucha no es capucha/ Submarino no es submarino/ Personal no es personal/ Parrilla no es parrilla/ Apretar no es apretar/ Quebrar no es quebrar/ Cantar no es cantar/ Volar no es volar/ Dormir no es dormir/ Limpiar no es limpiar/ Guerra no es guerra/ Cuerpo no es cuerpo/ Desaparecer no es desaparecer/ Morir no es morir/ Ser no es ser/ Yo, nada (210).
\end{abstract}

El poema, sostenido en el paralelismo y la enumeración de los métodos de tortura que se deja leer en el carácter plurisignificativo de los términos ("fierro", "capucha", "submarino", "parrilla", etc.), habilita diferentes lecturas. Por un lado, puede interpretarse que la estructura del terror evocada por medio de los mencionados recursos cae con todo su peso sobre el "yo", dejándola en una situación de despojo que sólo puede enunciarse como "nada". Se pone así de manifiesto el alcance de la violencia política a través de los sentidos que se han adherido al significado de las numerosas palabras evocadas, en términos de operación destructiva, también sobre el lenguaje. Por otro lado, el poema podría leerse como una respuesta que niega estos sentidos como efecto de la violencia. En esta dirección, la estructura "no es" puede interpretarse como una negación a aceptar esos otros sentidos. Así, "chupar" no es detener ilegalmente a una persona en un campo de concentración clandestino y "máquina" no es la picana, como un gesto de subsanar el lenguaje.

\title{
Conclusiones
}

¿Por qué pensar como parte del testimonio estas partes del texto constituidas por impresiones, poemas y notas donde emerge el territorio afectivo, íntimo? ¿No está acaso este territorio atravesado por la historia de la violencia que ha marcado la subjetividad, la identidad de la hija? ¿No asumen, por tanto, la expresión de lo íntimo y sus complejidades un valor político de reivindicación? ¿No están las acciones colectivas investidas también de la esfera personal, la emoción y los afectos? La expresión de lo íntimo es una interpretación de la (propia) historia, un relato que posibilita el anclaje a una hija 
cuya vida fracturada por la historia necesita reconstruir, reordenar, sabiendo de antemano que hay piezas que faltarán siempre.

La unión de fragmentos, la investigación, la lucha y las reflexiones se orientan a la recuperación del nombre propio: ser Ángela Urondo Raboy, hija de Alicia Raboy y Francisco Urondo. Cabe subrayar, en este sentido, la pregunta que, con tono violento, titula el texto: ¿Quién te creés que sos? La relación del nombre propio de persona con la identidad reconstruida responde a esta interpelación, desarmando su carácter retórico y dando lugar a la reinscripción de la protagonista en el orden genealógico que le corresponde y posibilitando así la reparación de su linaje: devolverse como hija de sus padres y devolverle a ellos, al mismo tiempo, su lugar de progenitores.

En un contexto globalizado de desplazamiento de las fronteras entre lo público y lo privado, donde, como señala Arfuch, se constata un rebasamiento de lo íntimo en lo público en términos de espectáculo, vale preguntarse, a partir del texto, qué consideramos por la producción de otros sentidos de expresión de lo íntimo que eluden lo espectacular y articulan, en cambio, nuevas formas de la relación sujeto-política, o de cómo los efectos de la historia han dado lugar al engendramiento de subjetividades específicas. En este sentido, es posible considerar la emergencia de un nuevo sujeto testigo que incorpora la intimidad con valor testimonial, transformando de este modo el género.

\section{Bibliografía}

Achúgar, Hugo. (2002). "Historias paralelas, historias ejemplares: la historia y la voz del otro". En Beverley, John \& Achúgar, Hugo. La voz del otro: testimonio, subalternidad y verdad narrativa. Guatemala: Universidad Rafael Landívar, pp. 61-84.

Agamben, Giorgio. (2000). Lo que queda de Auschwitz. El archivo y el testigo. Homo sacer III. España: Pre-Textos.

Alcoba, Laura. (2008). La casa de los conejos. Buenos Aires: Editorial Edhasa. (2014). El azul de las abejas. Buenos Aires: Editorial Edhasa.

Amar Sánchez, Ana María. (1990). "La ficción del testimonio", Iberoamericana, vol. LVI, no 151, pp. 447- 461.

Arfuch, Leonor. (2013). Memoria y autobiografía. Exploraciones en los límites. Argentina: FCE.

. (2016). "Cronotopías de la intimidad". En Arfuch, L. (Comp.).

Pensar este tiempo. Espacios, afectos, pertenencias. Argentina: Prometeo. 
Bajtín, Mijail. (2002). “El problema de los géneros discursivos”. En Estética de la creación verbal. Argentina: Siglo XXI Editores, pp. 248-293. . (1991). "Las formas del tiempo y el cronotopo en la novela". En Teoría y estética de la novela. España: Taurus, pp. 237-410.

Beverley, John. (2002). “Introducción”. En Beverley, John \& Achúgar, Hugo La voz del otro: testimonio, subalternidad y verdad narrativa. Guatemala: Universidad Rafael Landivar, pp. 17-32.

Bruzzone, Félix (2008). Los topos. Buenos Aires: Mondadori.

Carr, Robert. (2002). "Re-presentando el testimonio: notas sobre el cruce divisorio primer mundo/ tercer mundo". En Beverley, John \& Achúgar, Hugo. La voz del otro: testimonio, subalternidad y verdad narrativa. Guatemala: Universidad Rafael Landivar, pp. 85- 106.

Dalmaroni, Miguel. (2004). La palabra justa: literatura, crítica y memoria en la Argentina 1960-2002. Argentina y Chile: Melusina y RIL Editores.

Dillon, Marta. (2015). Aparecida. Argentina: Mondadori.

Fandiño, Laura. (2016). Acomodar la vida sobre esa arena tan movediza. Las memorias de los hijos en la literatura de Argentina y Chile. Córdoba, Argentina: Departamento Editorial de la Facultad de Lenguas, Universidad Nacional de Córdoba.

Hirsch, Marianne. (2015). La generación de la posmemoria. Escritura y cultura visual después del Holocausto. España: PanCrítica.

Jelin, Elizabeth. (2001). Los trabajos de la memoria. España: Siglo XXI Editores.

Pérez, Mariana Eva. (2012). Diario de una princesa montonera -110\% Verdad-. Buenos Aires: Capital Intelectual.

Randall, Margaret. (2002). “¿Qué es y cómo se hace un testimonio?” En Beverley, John \& Achúgar, Hugo. La voz del otro: testimonio, subalternidad y verdad narrativa. Guatemala: Universidad Rafael Landivar, pp. 33-60.

Ricœur, Paul. (2008). La memoria, la historia, el olvido. Argentina: FCE.

Robin, Regine. (2012). La memoria saturada. Argentina: Waldhuter Editores.

Sarlo, Beatriz. (2005). Tiempo pasado. Cultura de la memoria y giro subjetivo. Una discusión. Argentina, Buenos Aires: Siglo XXI Editores.

Semán, Ernesto. (2011). Soy un bravo piloto de la nueva China. Argentina: Sudamericana.

Urondo Raboy, Ángela. (2012). ¿Quién te creés que sos? Buenos Aires: Capital Intelectual. 